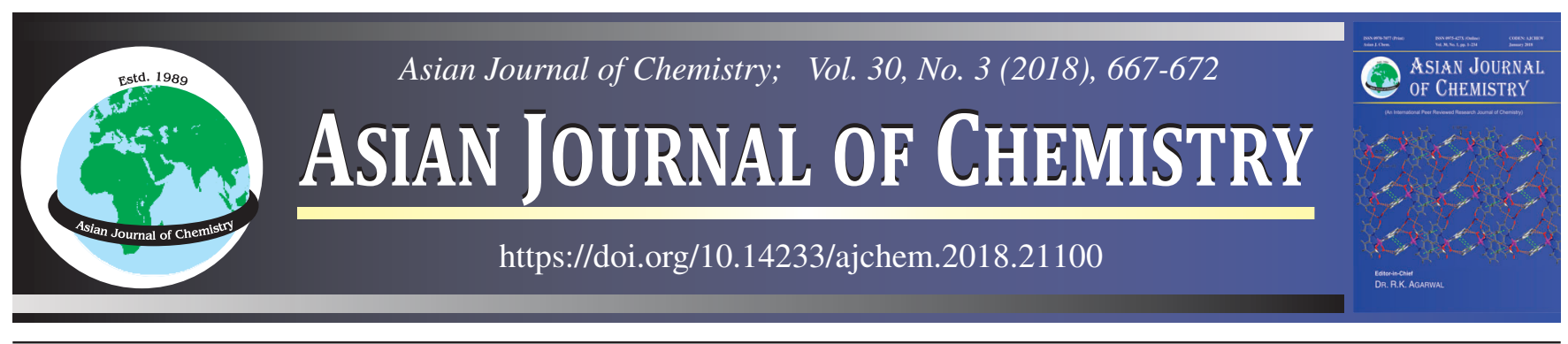

\title{
Synthesis and Characterization of Magnetized Clay Polymer Nanocomposites and its Adsorptive Behaviour in Removal of Chromium(VI) from Aqueous Phase
}

\section{E.J. Saravana Sundaram and P. Dharmalingam*}

PG and Research Department of Chemistry, Urumu Dhanalakshmi College, Tiruchirappalli-620 019, India

*Corresponding author: E-mail: dharmalingamudc@gmail.com

\begin{abstract}
The present study is focused on the preparation and characterization of magnetized polymer clay nanocomposites and its application in the removal of $\mathrm{Cr}(\mathrm{VI})$ from aqueous solution. Polymer clay composites were prepared from bentonite clay via in situ emulsion polymerization using methyl methaacrylate as monomer. The prepared polymer clay composites were magnetized by the incorporation of iron oxide nanoparticles. The magnetized polymer clay (MPC) nanocomposite was characterized by FT-IR, FE-SEM, VSM and TGA. Magnetized polymer clay nanocomposites had uniform distribution of iron oxide nanoparticles of size around $80 \mathrm{~nm}$ and had good thermal stability. Batch equilibrium studies were carried out and the experimental results were modelled using Langmuir, Freundlich and Temkin isotherm models. The maximum monolayer adsorption capacity was found to be $113 \mathrm{mg} / \mathrm{g}$ for the adsorption of $\mathrm{Cr}(\mathrm{VI})$ onto MPC nanocomposites. Kinetic studies were carried out and the data were tested with pseudo first-order and pseudo second-order equations. Adsorption of $\mathrm{Cr}(\mathrm{VI})$ onto the prepared nanocomposites was initially by film diffusion followed by intraparticle diffusion.
\end{abstract}

Keywords: Clay, Polymer, Magnetized clay, Nanocomposites, Hexavalent chromium, Adsorption.

\section{INTRODUCTION}

Chromium and its compounds are considered as most toxics for natural water system. Industrial effluents from leather tanning, textile dyeing, pigments and metal finishing industries are considered to be the major source of pollution by chromium compounds [1,2]. Hexavalent chromium is a proven carcinogen [3]. Hence, the removal of $\mathrm{Cr}(\mathrm{VI})$ from industrial effluents is the necessity before letting into the aquatic system. There are many physico-chemical methods such as ion-exchange, solvent extraction, reverse osmosis, adsorption, membrane separation are available for the treatment of effluents rich in $\mathrm{Cr}(\mathrm{VI})$ [4-7]. However, all these methods have their own merits and demerits [8]. Adsorption is one of the most simple method for removal of pollutants containing $\mathrm{Cr}(\mathrm{VI})$ due to its ease of operation, low initial cost and insensitivity to toxic substances [9-11]. Activated carbon is the most commonly used adsorbent for water purification due to its high surface area, porous structure and thermal stability. Owing to the high cost of commercially available activated carbon, various low cost adsorbents such as fly ash [12,13], clay mineral [14], etc. were explored.

Clays are easily available, low-cost and environmental friendly materials [15]. These clay materials have good structural properties, chemical and mechanical stability [16]. Recently, smectite and kaolinite group clays are widely investigated for their application as adsorbent materials. The smectite group of clays are composed of hydrated sodium calcium aluminum silicate, a family of non-metallic clays, which includes montmorillonite, bentonite, etc. [17]. However, the application of neat clay materials are often limited to the removal of cationic pollutants from aqueous phase because of their cation exchange capacity [18]. Hence, the surface modification of the clay may aid to overcome their drawbacks [19]. The modification of the clay materials by functionalizing and polymerizing them may result in enhancement of the adsorption capacity of the clay materials [20]. The efficiency of clay-polymer composites for water purification because of their superior structural and functional properties were investigated by many researchers [21]. However, the main disadvantage of using clay-polymer composites as adsorbents is its difficulty of separation of suspended clay polymers after use. Recently, the application of iron oxide nanoparticles in separation processes have attracted a lot of interest owing to their high surface area to volume ratio and ease of removal using external magnetic field after use [22].

The present study focuses on the preparation of polymer clay composites from bentonite clay via in situ emulsion polymerization using methyl methacrylate as monomer. Iron oxide nanoparticles were incorporated over the surface of the composites for aiding the recovery of the spent adsorbent materials. The prepared magnetized polymer clay (MPC) nanocomposites 
were characterized using FT-IR, VSM, FE-SEM and TGA. The efficiency of the prepared adsorbent composites for the removal of $\mathrm{Cr}(\mathrm{VI})$ was investigated by performing batch adsorption equilibrium and kinetic studies.

\section{EXPERIMENTAL}

Preparation of polymer clay composites: Bentonite clay was prepared via ion-exchange reaction, by dispersing clay in deionized water at $25^{\circ} \mathrm{C}$ and mixed for $1 \mathrm{~h}$. Tetrabutylammonium bromide (TBAB) was then added to the suspension and the mixture stirred for $24 \mathrm{~h}$ and filtered using disc filter funnel. The modified clay was washed for several times with redistilled water and dried at $80{ }^{\circ} \mathrm{C}$ for $24 \mathrm{~h}$. Prepared organoclay was dispersed in water and mixed with monomer methyl methacrylate then suspension was then stirred for $2 \mathrm{~h}$ at $80^{\circ} \mathrm{C}$. The initiator and the surfactant were then added to the solution and refluxed for $4 \mathrm{~h}$ at the same temperature. The solution was then allowed to cool, washed for several times with water and methanol using disk funnel. The substrate is then dried at $170{ }^{\circ} \mathrm{C}$ in vacuum oven for about $30 \mathrm{~min}$.

Magnetized polymer clay nanocomposites: Initially, a suspension was made by dissolving $2.78 \mathrm{~g}$ of $\mathrm{FeSO}_{4}$ in 100 $\mathrm{mL}$ of double distilled water. Polymer clay composites $(0.5 \mathrm{~g})$ were added to this suspension under constant stirring. Then $10 \mathrm{~mL}$ of $10 \% \mathrm{NaOH}$ solution was added dropwise to the suspension to precipitate hydrated iron oxide in a magnetic stirred. The solution was then stirred and heated to $100^{\circ} \mathrm{C}$ for $1 \mathrm{~h}$ followed by cooling to room temperature. The magnetized adsorbent is washed repeatedly with double distilled water until the $\mathrm{pH}$ become neutral and dried in a hot air oven. The resultant magnetized polymer clay nanocomposites was stored in an air tight container for further use.

Characterization of magnetized polymer clay nanocomposites: The magnetized polymer clay nanocomposites were characterized by FT-IR, FE-SEM, VSM and TGA techniques. FT-IR analysis was performed in Bruker-Tensor 27 FTIR spectrometer. FE-SEM micrographs were obtained from FESEM-SUPRA, Carl Zeiss, Germany in standard high vacuum conditions. Thermal stability of MPC nanocomposites was analyzed using TGA Q50 V20.13 Build 39 purchased from TA instruments, USA. VSM analysis were carried out on EG\&G Princeton Applied Research VSM MODEL 4500, vibrating sample magnetometer with a maximum field of $7 \mathrm{k}$ Oe at room temperature.

Adsorption experiments: Equilibrium experiments were carried out by varying the initial $\mathrm{Cr}(\mathrm{VI})$ concentrations in the desired range with a fixed MPC nanocomposites dosage for $24 \mathrm{~h}$ at $300 \mathrm{~K}$. The amount of $\mathrm{Cr}(\mathrm{VI})$ after adsorption was measured by indirect UV-Visible spectrophotometer (Shimadzu UV-2102 PC, Japan) as reported elsewhere [23].

Amount of $\mathrm{Cr}(\mathrm{VI})$ adsorbed at equilibrium was calculated as follows:

$$
\mathrm{q}_{\mathrm{e}}=\frac{\left(\mathrm{C}_{\mathrm{o}}-\mathrm{C}_{\mathrm{e}}\right) \mathrm{V}}{\mathrm{W}}
$$

Kinetic experiments were carried by withdrawing the samples at regular time intervals and measuring the residual $\mathrm{Cr}(\mathrm{VI})$ concentration. It was carried out for four different initial concentration of $\mathrm{Cr}(\mathrm{VI})$ solutions. Magnetized polymer clay nanocomposites dosage, aqueous phase $\mathrm{pH}$ and initial concentration of adsorbates were fixed constant.

Amount of $\mathrm{Cr}(\mathrm{VI})$ adsorbed at time (t) was calculated as follows:

$$
\mathrm{q}_{\mathrm{e}}=\frac{\left(\mathrm{C}_{\mathrm{o}}-\mathrm{C}_{\mathrm{t}}\right) \mathrm{V}}{\mathrm{W}}
$$

where $C_{o}$ and $C_{e}(m g / L)$ are the liquid phase initial and equilibrium concentrations of $\mathrm{Cr}(\mathrm{VI})$, respectively; $\mathrm{C}_{\mathrm{t}}(\mathrm{mg} / \mathrm{L})$ is the liquid phase concentration of $\mathrm{Cr}(\mathrm{VI})$ at time ' $\mathrm{t}$ '; $\mathrm{v}$ is the volume of the solution (L), and $w$ is the mass of magnetized polymer clay nanocomposites used (g). All the experiments were duplicated and the experimental results were within $5 \%$ error.

\section{RESULTS AND DISCUSSION}

Characterization of magnetized polymer clay (MPC) nanocomposites: The prepared MPC nanocomposites were characterized by various sophisticated techniques like FT-IR, FE-SEM, VSM and TGA. The FR-IR spectra is shown in Fig. 1. The strong adsorption band at 2911 and $2842 \mathrm{~cm}^{-1}$ correspond to $\mathrm{CH}_{3}$ and $\mathrm{CH}_{2}$ groups, respectively. The strong peaks at 1462 and $1631 \mathrm{~cm}^{-1}$ correspond to $\mathrm{OH}$ band for the water molecules adsorption on the clay surface. The peak at $3698 \mathrm{~cm}^{-1}$ confirms the dominance of dioctahedral smectite with $[\mathrm{Al}, \mathrm{Al}-\mathrm{OH}]$ stretching and bending bands. The strong absorption band in the 1031 $\mathrm{cm}^{-1}$ region corresponds to the silicate structure. Bands at 534$465 \mathrm{~cm}^{-1}$ can be assigned to [Si-O-Fe], [SiO], [Si-O-Al]. The FE-SEM micrograph of MPC nanocomposites is shown in Fig. 2. It could be inferred that the magnetite nanoparticles were evenly distributed over the surface of the clay polymer composites.

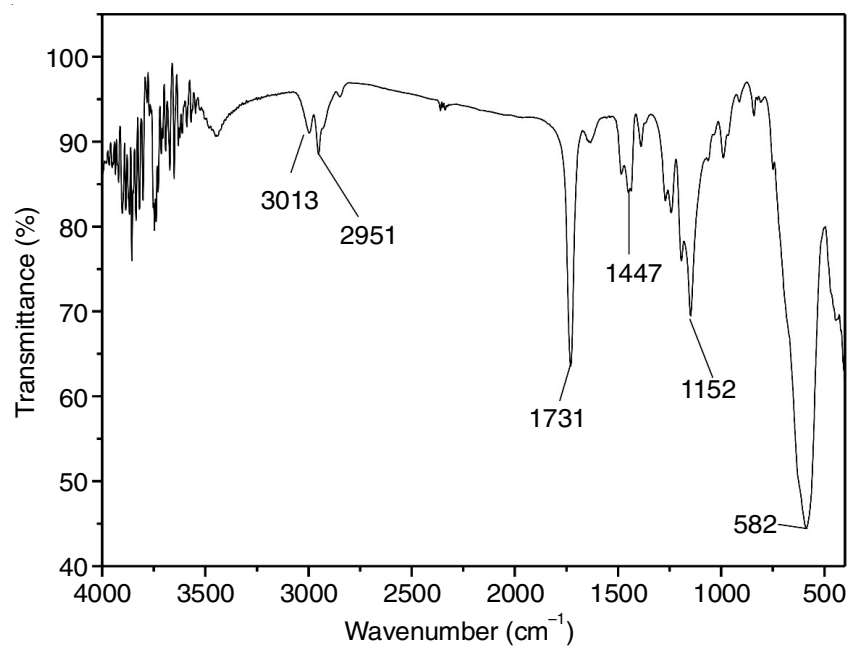

Fig. 1. FT-IR spectra of magnetized polymer clay (MPC) nanocomposites

The size distribution of these magnetite nanoparticles was approximately $80 \mathrm{~nm}$ and cubic in shape. The saturation magnetization value of MPC nanocomposites was found to be 0.9324 emu/g as shown in VSM curve (Fig. 3). Thermogravimetric analysis of the prepared MPC was carried out and the obtained thermogram is shown in Fig. 4. The thermogram proved that the prepared MPC nanocomposites were thermally stable. The absence of considerable weight loss at around $100^{\circ} \mathrm{C}$ suggested that the prepared sample had very minimal presence of water 


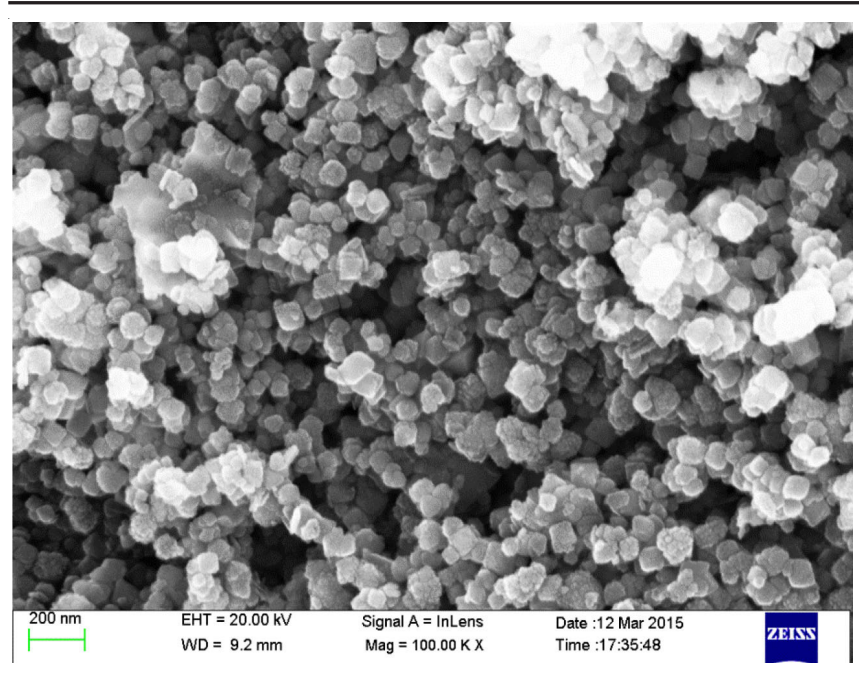

Fig. 2. FE-SEM micrograph of MPC nanocomposites

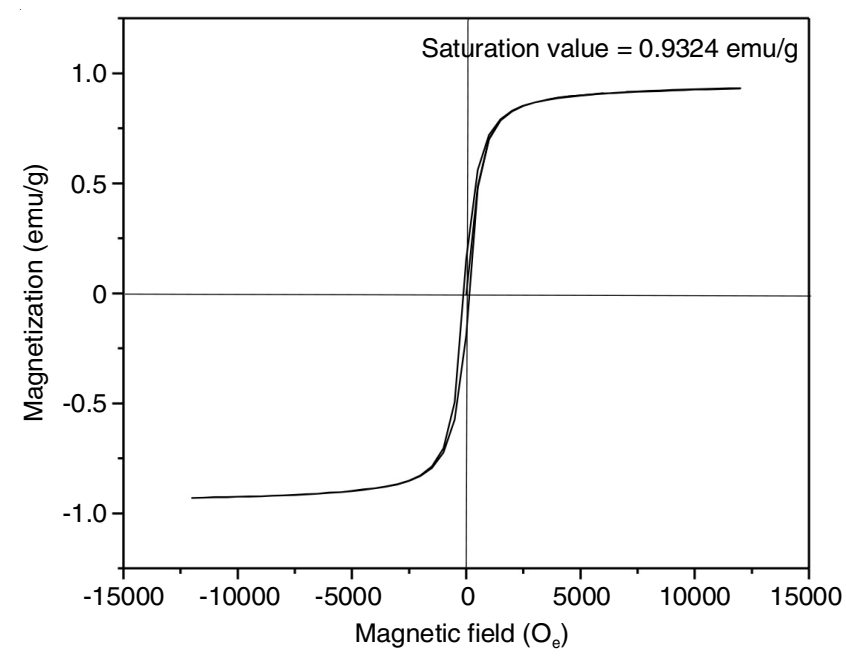

Fig. 3. VSM curve of MPC nanocomposites

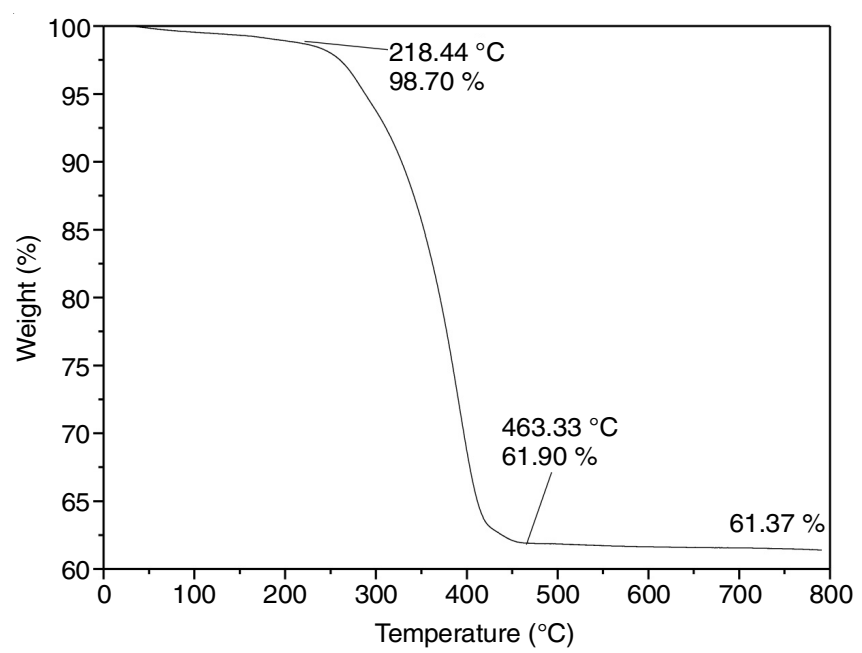

Fig. 4. TGA thermogram of MPC nanocomposites

molecules. On further heating, the prepared adsorbent sample possessed $98 \%$ stability at $218{ }^{\circ} \mathrm{C}$. The $40 \%$ weight loss at $463{ }^{\circ} \mathrm{C}$ marked by the steep part of the curve can be attributed to the removal of carbon from the sample as carbon dioxide. Further heating did not result in further weight loss. At as high as $800{ }^{\circ} \mathrm{C}, 61 \%$ of the sample remained unaffected. Thus, the
TGA analysis proved that the MPC nanocomposites had high thermal stability.

Batch adsorption studies: Preliminary batch studies were carried out for the adsorption of $\mathrm{Cr}(\mathrm{VI})$ onto MPC nanocomposites by varying the parameters such as initial aqueous phase $\mathrm{pH}, \mathrm{MPC}$ dosage and initial $\mathrm{Cr}(\mathrm{VI})$ concentration. The initial $\mathrm{pH}$ varied from 2 to 12 with a fixed MPC dosage of $0.05 \mathrm{~g}$ for the adsorption of $10 \mathrm{~mL}$ of $10 \mathrm{mg} / \mathrm{L} \mathrm{Cr}(\mathrm{VI})$ solution. The results showed that $\mathrm{Cr}(\mathrm{VI})$ was maximum adsorbed at $\mathrm{pH} 2$ (Fig. 5). This is because most of the $\mathrm{Cr}(\mathrm{VI})$ ions are cations $\left(\left[\mathrm{HCrO}_{4}\right]^{-}\right.$ or $\left[\mathrm{Cr}_{2} \mathrm{O}_{7}\right]^{2-}$ at acidic $\mathrm{pH}$ [24]. Hence, these cationic species of $\mathrm{Cr}$ (VI) was better adsorbed onto the surface of MPC nanocomposites at $\mathrm{pH} 2$. At higher $\mathrm{pH}$, there may be the suppression in the hydrolysis of chromium ions leading to a lower \% of adsorption. Hence, the further experiments were conducted at $\mathrm{pH} 2$. The effect of MPC dosage on the adsorption of $\mathrm{Cr}(\mathrm{VI})$ was evaluated by varying the adsorbent dosage from $0.01 \mathrm{~g}$ to $1 \mathrm{~g} / 10 \mathrm{~mL}$ of $10 \mathrm{mg} / \mathrm{L} \mathrm{Cr}$ (VI) solution. The increase in the adsorbent dosage lead to the increase in the available surface area for adsorption thereby resulting in the increase in adsorption percentage of $\mathrm{Cr}$ (VI) molecules. The influence of initial adsorbate concentration on the adsorption process was also studied by varying the initial Cr(VI) concentration from 100 to $1000 \mathrm{mg} / \mathrm{L}$ with a fixed MPC dosage of $0.1 \mathrm{~g} / 10 \mathrm{~mL}$. It was observed that \% adsorption of $\mathrm{Cr}(\mathrm{VI})$ onto MPC nanocomposites decreased with the increase in the initial adsorbate concentration.

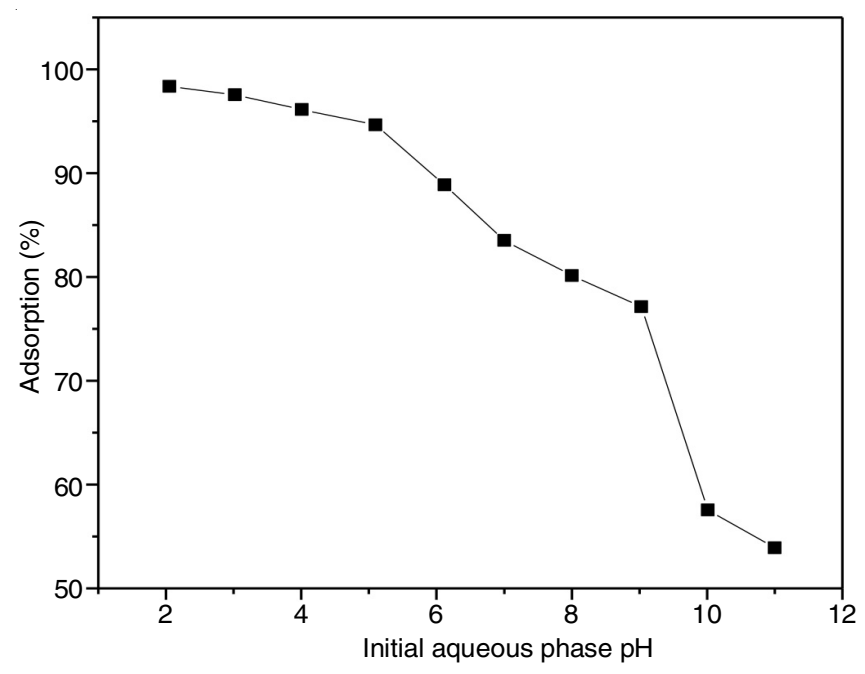

Fig. 5. Effect of initial aqueous phase $\mathrm{pH}$ on the adsorption of $\mathrm{Cr}(\mathrm{VI})$ onto MPC nanocomposites (ads. dosage $=0.1 \mathrm{~g} / 10 \mathrm{~mL} ;[\mathrm{Cr}(\mathrm{VI})]_{0}=10$ $\mathrm{mg} / \mathrm{L} ; \mathrm{T}=300 \mathrm{~K} ; \mathrm{t}=24 \mathrm{~h}$; agitation speed $=100 \mathrm{rpm}$ )

Adsorption isotherms: The extent of the distribution of metal ions between the aqueous phase and the solid adsorbent surface determines the position of equilibrium in the adsorption process. This can be expressed by well-known adsorption isotherm models such as Langmuir, Freundlich and Temkin isotherms.

Langmuir isotherm assumes homogeneous binding where adsorption occurs only at specific sites that are identical and have equivalent adsorption capacities. The general equation of Langmuir isotherm is represented as [25]:

$$
\mathrm{q}_{\mathrm{e}}=\frac{\mathrm{K}_{\mathrm{L}} \mathrm{C}_{\mathrm{e}} \mathrm{q}_{\mathrm{m}}}{1+\mathrm{q}_{\mathrm{m}} \mathrm{C}_{\mathrm{e}}}
$$


The dimensionless separation factor $\mathrm{R}_{\mathrm{L}}$ is an important aspect of Langmuir isotherm as it is the indication of type of the adsorption process (unfavourable $\left(\mathrm{R}_{\mathrm{L}}>1\right)$, linear $\left(\mathrm{R}_{\mathrm{L}}=1\right)$, favourable $\left(0<\mathrm{R}_{\mathrm{L}}<1\right)$ or irreversible $\left(\mathrm{R}_{\mathrm{L}}=0\right)$.

$$
\mathrm{R}_{\mathrm{L}}=\frac{1}{1+\mathrm{K}_{\mathrm{L}} \mathrm{C}_{\mathrm{o}}}
$$

Freundlich isotherm is not restricted to monolayer adsorption process. It can be applied to multilayer adsorption with nonuniform binding of adsorbate molecules over the heterogeneous surface of the adsorbent [26].

$$
\mathrm{q}_{\mathrm{e}}=\mathrm{K}_{\mathrm{F}} \mathrm{C}_{\mathrm{e}}^{1 / \mathrm{n}}
$$

Temkin isotherm assumes that heat of adsorption of all the molecules would decrease linearly with the surface coverage. This isotherm model can be better applicable in the prediction of solid-gas adsorption rather than solid-liquid interactions. However, Temkin isotherm is used for modelling the studied adsorption process, since it has a factor which represents to the binding energy of adsorption.

The general equation of this isotherm is given as [27]:

$$
\mathrm{q}_{\mathrm{e}}=\frac{\mathrm{RT}}{\mathrm{b}} \ln \left(\mathrm{K}_{\mathrm{T}} \mathrm{C}_{\mathrm{e}}\right)
$$

where $\mathrm{q}_{\mathrm{e}}(\mathrm{mg} / \mathrm{g})$ is the amount of metal ions adsorbed at equilibrium. The constant $\mathrm{K}_{\mathrm{L}}(\mathrm{L} / \mathrm{mg})$ is the Langmuir constant and $\mathrm{q}_{\mathrm{m}}(\mathrm{mg} / \mathrm{g})$ denotes the maximum monolayer capacity. $\mathrm{K}_{\mathrm{F}}(\mathrm{L} /$ $\mathrm{g})$ is the Freundlich constant and $\mathrm{n}(\mathrm{g} / \mathrm{L})$ is the Freundlich exponent. The value of $n$ should range from 1 to 10 for the adsorption process to be favourable. The Temkin isotherm parameters $\mathrm{K}_{\mathrm{T}}$ (L/mg) represents the equilibrium binding constant corresponding to the maximum binding energy.

Inference from isotherm studies: The experimental data were fitted with non-linear isotherm models and the model parameters were predicted by using solver add in from Microsoft excel. The plots for Langmuir, Freundlich and Temkin isotherm models were compared with the experimental data as shown in Fig. 6. The predicted equilibrium data using different isotherm models are given in Table-1. From Fig. 6, it can be inferred that the plot for Freundlich isotherm was closer to the experimental data.

This was again confirmed from chi-squared values from

\begin{tabular}{|c|c|}
\hline $\begin{array}{r}\text { LANGMU } \\
\text { ISOTHERM P } \\
\text { OF Cr(VI) }\end{array}$ & $\begin{array}{l}\text { TEMKIN } \\
\text { DSORPTION } \\
\text { POSITES }\end{array}$ \\
\hline \multicolumn{2}{|c|}{ Langmuir isotherm } \\
\hline $\mathrm{q}_{\mathrm{m}}(\mathrm{mg} / \mathrm{g})$ & 113.11 \\
\hline $\mathrm{K}_{\mathrm{L}}$ & 0.0027 \\
\hline $\mathrm{R}_{\mathrm{L}}$ & 0.2702 \\
\hline$\chi^{2}$ & 0.8352 \\
\hline \multicolumn{2}{|c|}{ Freundlich isotherm } \\
\hline $\mathrm{K}_{\mathrm{F}}(\mathrm{L} / \mathrm{g})$ & 0.8272 \\
\hline $\mathrm{n}$ & 1.3855 \\
\hline$\chi^{2}$ & 0.2260 \\
\hline \multicolumn{2}{|c|}{ Temkin isotherm } \\
\hline $\mathrm{B}_{1}$ & 15.554 \\
\hline $\mathrm{K}_{\mathrm{T}}(\mathrm{L} / \mathrm{mg})$ & 0.066 \\
\hline$\chi^{2}$ & 7.6226 \\
\hline
\end{tabular}
Table-1. Since, the error values are lesser for Freundlich isotherm when compared to Langmuir and Temkin isotherm models.

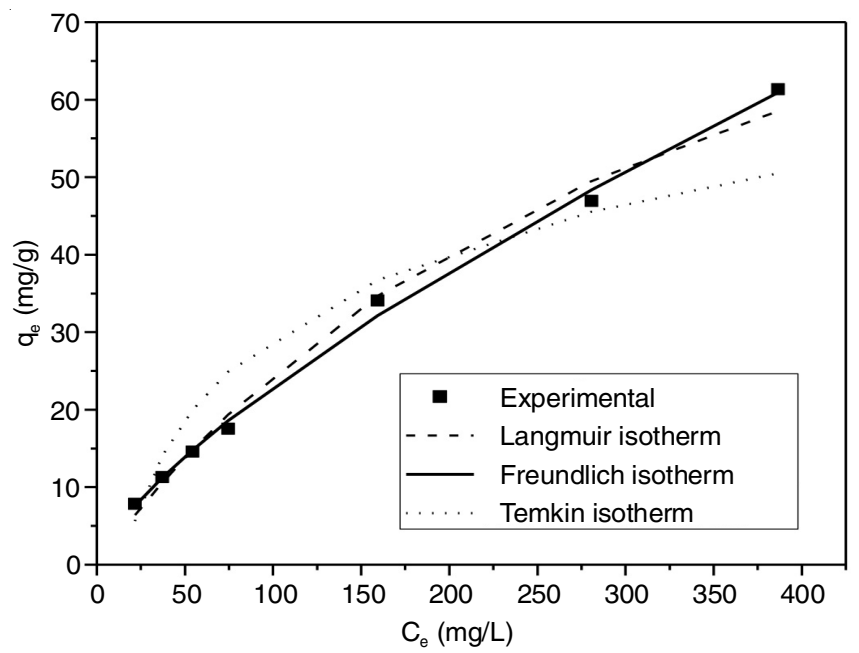

Fig. 6. Adsorption isotherm plots for the adsorption of $\mathrm{Cr}(\mathrm{VI})$ onto MPC nanocomposites (ads. dosage $=0.1 \mathrm{~g} / 10 \mathrm{~mL} ; \mathrm{pH} 2 ; \mathrm{T}=300 \mathrm{~K} ; \mathrm{t}=$ $24 \mathrm{~h}$; agitation speed $=100 \mathrm{rpm}$ )

Hence, it could be concluded that the studied adsorption process followed Freundlich isotherm model thereby indicating that the adsorption of $\mathrm{Cr}(\mathrm{VI})$ onto MPC nanocomposites was by multilayer binding. The $\mathrm{q}_{\mathrm{m}}$ value of Langmuir isotherm indicated that $113 \mathrm{mg}$ of $\mathrm{Cr}(\mathrm{VI})$ can be adsorbed per gram of the prepared MPC nanocomposites. The $R_{L}$ value of Langmuir isotherm model was 0.2702 suggesting that the adsorption process was favourable. This was again proved by the value of Freundlich exponent $(\mathrm{n}=1.38)$.

Adsorption kinetic studies: Adsorption dynamics explains the solute uptake rate of the adsorbent material. The kinetics of $\mathrm{Cr}(\mathrm{VI})$ removal by MPC nanocomposites was studied for four different initial adsorbate concentrations such as 25, 50, 75 and $100 \mathrm{mg} / \mathrm{L}$. An increase in adsorption percentage of $\mathrm{Cr}(\mathrm{VI})$ was observed with the increase in the contact time. The rate of adsorption was rapid during initial time and it decreased as the time increased signaling the equilibration. The kinetic data were analyzed using pseudo first-order and pseudo secondorder kinetic equations.

The linear form of Lagergren's pseudo first-order kinetic equation [28], which describes solid-liquid interactions is given as:

$$
\ln \left(\mathrm{q}_{\mathrm{e}}-\mathrm{q}_{\mathrm{t}}\right)=\ln \mathrm{q}_{\mathrm{e}}-\mathrm{k}_{1} \mathrm{t}
$$

The linear form of pseudo second-order kinetic equation which is used for studying the chemisorption kinetics [29] is expressed as:

$$
\frac{\mathrm{t}}{\mathrm{q}_{\mathrm{t}}}=\frac{1}{\mathrm{k}_{2} \mathrm{q}_{\mathrm{e}}^{2}}+\frac{1}{\mathrm{q}_{\mathrm{e}}} \mathrm{t}
$$

where $\mathrm{k}_{1}(1 / \mathrm{min})$ and $\mathrm{k}_{2}(\mathrm{~g} / \mathrm{mg} \min )$ are pseudo-first-order and pseudo-second-order rate constants, respectively.

Inference from kinetic models: The pseudo first-order and pseudo second-order kinetic plots are shown in Figs. 7 and 8 , respectively. The kinetic model parameters are given in Table-2. It can be inferred that the experimental data had better fit with pseudo second-order rate equation when compared to pseudo first-order rate equation for all the four studied concentrations. Thus, the adsorption of $\mathrm{Cr}(\mathrm{VI})$ onto MPC nanocomposites can be considered to be a chemisorption process. The pseudo 


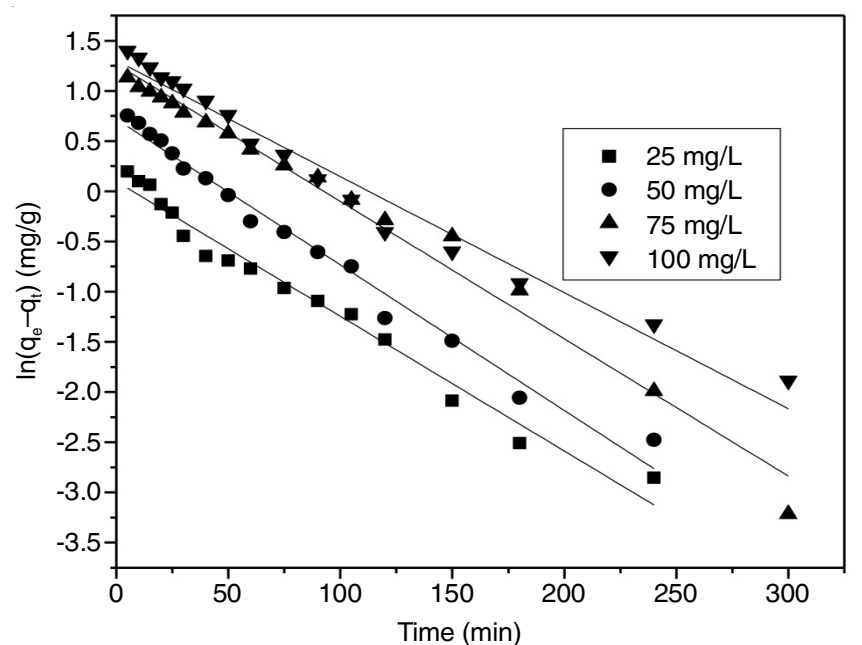

Fig. 7. Pseudo first-order plot for the adsorption of $\mathrm{Cr}(\mathrm{VI})$ onto MPC nanocomposites (ads. dosage $=1.5 \mathrm{~g} / 150 \mathrm{~mL} ; \mathrm{pH} 2.0 ; \mathrm{T}=300 \mathrm{~K}$; agitation $=150 \mathrm{rpm})$

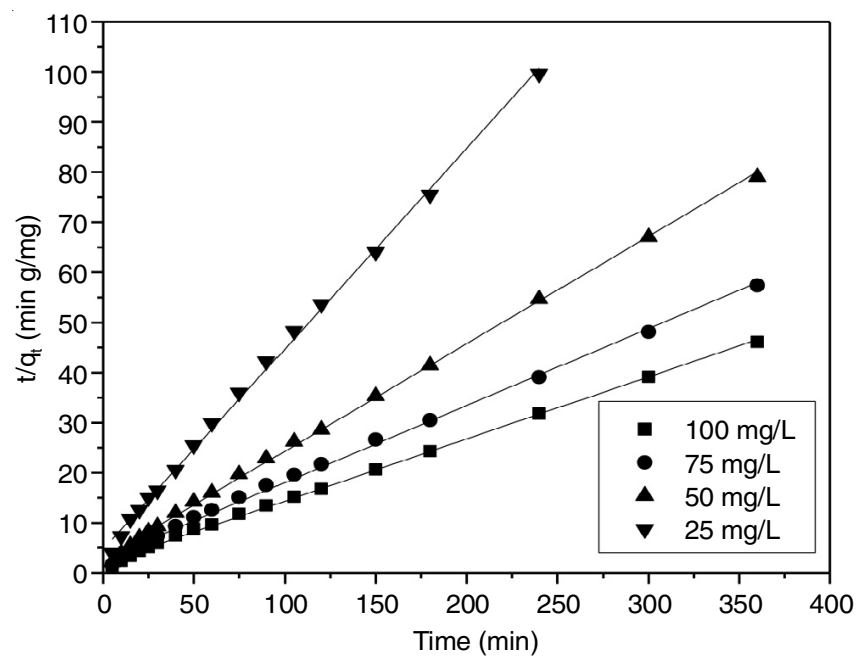

Fig. 8. Pseudo second-order plot for the adsorption of $\mathrm{Cr}(\mathrm{VI})$ onto MPC nanocomposites (ads. dosage $=1.5 \mathrm{~g} / 150 \mathrm{~mL} ; \mathrm{pH} 2.0 ; \mathrm{T}=300 \mathrm{~K}$; agitation $=150 \mathrm{rpm}$ )

TABLE-2

KINETIC MODEL PARAMETERS FOR THE ADSORPTION OF Cr(VI) ONTO MPC NANOCOMPOSITES

\begin{tabular}{ccccc}
\multirow{2}{*}{$\begin{array}{c}\text { Kinetic model } \\
\text { parameters }\end{array}$} & \multicolumn{5}{c}{ Initial Cr(VI) concentration $(\mathrm{mg} / \mathrm{L})$} \\
\cline { 2 - 5 } & 25 & 50 & 75 & 100 \\
\hline \multicolumn{5}{c}{ Pseudo first-order model } \\
$\mathrm{k}_{1}(\mathrm{~L} / \mathrm{min})$ & 0.0134 & 0.0145 & 0.0136 & 0.0115 \\
$\mathrm{q}_{\mathrm{e}}(\mathrm{mg} / \mathrm{g})$ & 1.1026 & 2.0493 & 3.5519 & 3.6755 \\
$\mathrm{r}^{2}$ & 0.97431 & 0.98304 & 0.9828 & 0.97329 \\
\hline \multicolumn{5}{c}{ Pseudo second-order model } \\
\hline $\mathrm{k}_{2}(\mathrm{~g} / \mathrm{mg}$ min $)$ & 0.0339 & 0.0019 & 0.0087 & 0.0078 \\
$\mathrm{q}_{\mathrm{e}}(\mathrm{mg} / \mathrm{g})$ & 2.4996 & 4.6657 & 6.5112 & 8.0677 \\
$\mathrm{r}^{2}$ & 0.9978 & 0.9989 & 0.9971 & 0.9985 \\
\hline
\end{tabular}

second-order rate constant $\left(\mathrm{k}_{2}\right)$ was found to decrease with the increase in the initial $\mathrm{Cr}(\mathrm{VI})$ concentration.

Adsorption mechanism: The adsorption mechanism for the uptake of $\mathrm{Cr}(\mathrm{VI})$ metal ions by MPC nanocomposites was studied by fitting the kinetic data with intraparticle diffusion model and Boyd equation.

The general form of intraparticle diffusion model [30] is as follows:

$$
\mathrm{q}_{\mathrm{t}}=\mathrm{k}_{\mathrm{i}} \mathrm{t}^{1 / 2}+\mathrm{C}
$$

where $\mathrm{k}_{\mathrm{i}}\left(\mathrm{mg} / \mathrm{g} \min ^{1 / 2}\right)$ is the rate constant of intraparticle diffusion model and $\mathrm{C}(\mathrm{mg} / \mathrm{g})$ represents the boundary layer thickness.

The intraparticle diffusion plot for all the four studied concentrations are shown in Fig. 9. It can be inferred that the plots have three linear portions. The first linear portion which represents the initial period of adsorption represents the diffusion of adsorbate molecules to the surface of adsorbent. The second linear portion is due to the intraparticle diffusion. The third linear portion is the representation of attainment of equilibrium.

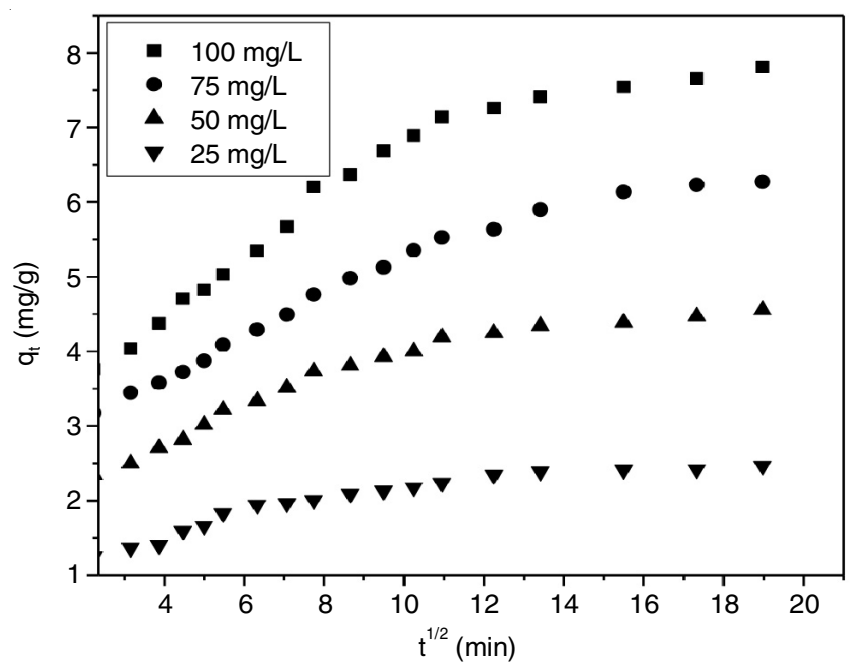

Fig. 9. Intraparticle diffusion model plots for the adsorption of $\mathrm{Cr}(\mathrm{VI})$ onto MPC nanocomposites (ads. dosage $=1.5 \mathrm{~g} / 150 \mathrm{~mL} ; \mathrm{pH} 2.0 ; \mathrm{T}=$ $300 \mathrm{~K}$; agitation $=150 \mathrm{rpm}$ )

Boyd plot gives a better insight about the rate controlling step of the adsorption process. Boyd plot [31] is represented as:

$$
\mathrm{B}_{\mathrm{t}}=-0.4977-\ln (1-\mathrm{F})
$$

where $\mathrm{F}$ is the fraction of solute adsorbed at time $t ; B_{t}$ is the mathematical function of $\mathrm{F}$. When the plots for Boyd equation are linear and passes through the origin, the rate of adsorption process will be controlled by intraparticle diffusion.

The Boyd plot for adsorption of $\mathrm{Cr}(\mathrm{VI})$ onto MPC nanocomposite for all the four studied concentrations are given in Fig. 10. It can be seen that the plots are non-linear and did not pass through the origin suggesting that the boundary layer diffusion is the rate controlling step in the studied adsorption process.

\section{Conclusion}

The magnetized polymer clay (MPC) nanocomposites were prepared by emulsion polymerization using bentonite clay and methyl methacrylate. The prepared adsorbent was characterized by FT-IR, FE-SEM, TGA and VSM. The thermal stability of adsorbent was evident from the TGA thermogram. The efficiency of the prepared adsorbent was evaluated for the removal of $\mathrm{Cr}(\mathrm{VI})$ from aqueous solution. Separation factor of Langmuir isotherm model $\left(0<\mathrm{R}_{\mathrm{L}}<1\right)$ and Freundlich exponent ( $\mathrm{n}=1$ to 10 ) proved that adsorption of $\mathrm{Cr}(\mathrm{VI})$ onto MPC nanocomposites was favourable. Kinetic data suggested that the studied adsorption process followed pseudo secondorder rate equation. The mechanism of adsorption process was 


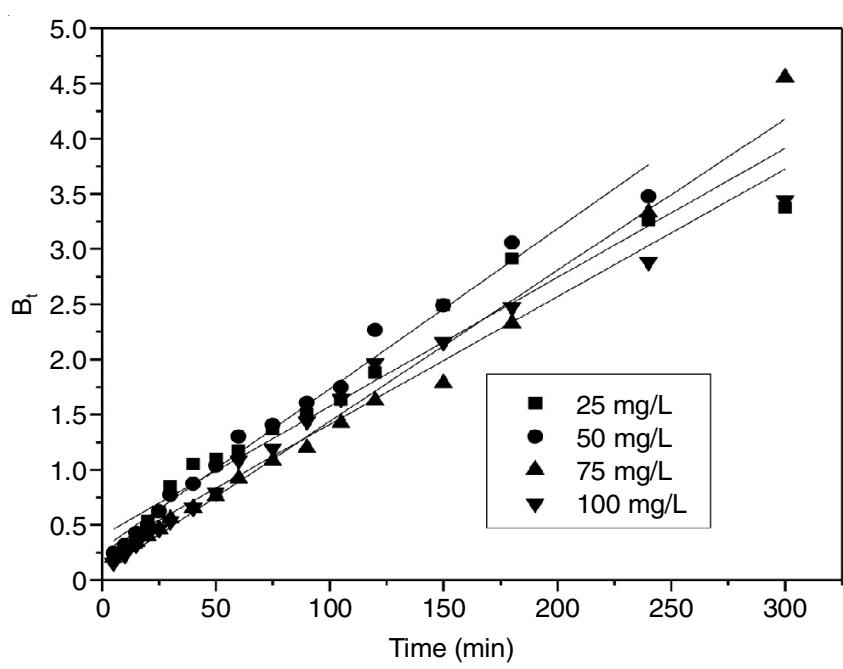

Fig. 10. Boyd plot for the adsorption of $\mathrm{Cr}(\mathrm{VI})$ onto MPC nanocomposites (ads. dosage $=1.5 \mathrm{~g} / 150 \mathrm{~mL} ; \mathrm{pH} 2.0 ; \mathrm{T}=300 \mathrm{~K}$; agitation $=150$ rpm)

studied by testing the kinetic data with intraparticle diffusion model and Boyd plot. The rate limiting step for the uptake of $\mathrm{Cr}(\mathrm{VI})$ moieties by MPC nanocomposites was the film diffusion step. The prepared MPC nanocomposites proved to be an efficient adsorbent for the removal of $\mathrm{Cr}(\mathrm{VI})$ from aqueous solution.

\section{REFERENCES}

1. V.K. Gupta, A. Rastogi and A. Nayak, J. Colloid Interface Sci., 342, 135 (2010); https://doi.org/10.1016/j.jcis.2009.09.065.

2. W.Q. Wang, M.Y. Li and Q.X. Zeng, Trans. Nonferr. Met. Soc. China, 22, 2831 (2012);

https://doi.org/10.1016/S1003-6326(11)61539-2.

3. D.E. Kimbrough, Y. Cohen, A.M. Winer, L. Creelman and C.A. Mabuni, Crit. Rev. Environ. Sci. Technol., 29, 1 (1999); https://doi.org/10.1080/10643389991259164.

4. S. Rengaraj, K.H. Yeon and S.H. Moon, J. Hazard. Mater, 87, 273 (2001); https://doi.org/10.1016/S0304-3894(01)00291-6.

5. R. Rautenbach and T. Linn, Desalination, 105, 63 (1996); https://doi.org/10.1016/0011-9164(96)00059-8.

6. S. Karagoz, T. Tay, S. Ucar and M. Erdem, Bioresour. Technol., 99, 6214 (2008);

https://doi.org/10.1016/j.biortech.2007.12.019.

7. C. Chiemchaisri and K. Yamamoto, J. Membr. Sci., 87, 119 (1994); https://doi.org/10.1016/0376-7388(93)E0090-Z.

8. V. Vimonses, S. Lei, B. Jin, C.W.K. Chow and C. Saint, Appl. Clay Sci., 43, 465 (2009); https://doi.org/10.1016/j.clay.2008.11.008.
9. V. Meshko, L. Markovska, M. Mincheva and A.E. Rodrigues, Water Res., 35, 3357 (2001); https://doi.org/10.1016/S0043-1354(01)00056-2.

10. E. Forgacs, T. Cserháti and G. Oros, Environ. Int., 30, 953 (2004); https://doi.org/10.1016/j.envint.2004.02.001.

11. V.K. Garg, R. Kumar and R. Gupta, Dyes Pigments, 62, 1 (2004); https://doi.org/10.1016/j.dyepig.2003.10.016.

12. S.B. Wang and H. Li, J. Hazard. Mater, 126, 71 (2005); https://doi.org/10.1016/j.jhazmat.2005.05.049.

13. P. Janos, H. Buchtova and M. Ryznarova, Water Res., 37, 4938 (2003); https://doi.org/10.1016/j.watres.2003.08.011.

14. C.C. Wang, L.C. Juang, T.C. Hsu, C.K. Lee, J.F. Lee and F.C. Huang, J. Colloid Interface Sci., 273, 80 (2004); https://doi.org/10.1016/j.jcis.2003.12.028.

15. H.B. Bradl, J. Colloid Interface Sci., 277, 1 (2004); https://doi.org/10.1016/j.jcis.2004.04.005.

16. H.H. Murray, Appl. Clay Sci., 17, 207 (2000); https://doi.org/10.1016/S0169-1317(00)00016-8.

17. P. Liu and L. Zhang, Sep. Purif. Technol., 58, 32 (2007); https://doi.org/10.1016/i.seppur.2007.07.007.

18. M.A. Barakat, Arab. J. Chem., 4, 361 (2011); https://doi.org/10.1016/j.arabjc.2010.07.019.

19. L. Wang and A. Wang, J. Hazard. Mater., 160, 173 (2008); https://doi.org/10.1016/j.jhazmat.2008.02.104.

20. G.B.B. Varadwaj, K. Parida and V.O. Nyamori, Inorg. Chem. Front., 3, 1100 (2016); https://doi.org/10.1039/C6QI00179C

21. E.I. Unuabonah and A. Taubert, Appl. Clay Sci., 99, 83 (2014); https://doi.org/10.1016/j.clay.2014.06.016.

22. V.K. Gupta, S. Agarwal and T.A. Saleh, Water Res., 45, 2207 (2011); https://doi.org/10.1016/j.watres.2011.01.012.

23. Z. Yue, S.E. Bender, J. Wang and J. Economy, J. Hazard. Mater., 166, 74 (2009); https://doi.org/10.1016/j.jhazmat.2008.10.125.

24. D. Zhao, A.K. Sen Gupta and L. Stewart, Ind. Eng. Chem. Res., 37, 4383 (1998); https://doi.org/10.1021/ie980227r.

25. I. Langmuir, J. Am. Chem. Soc., 40, 1361 (1918); https://doi.org/10.1021/ja02242a004.

26. H.M.F. Freundlich, Z. Phys. Chem., 57U, 385 (1906); https://doi.org/10.1515/zpch-1907-5723.

27. R.R. Sheha and E. Metwally, J. Hazard. Mater, 143, 354 (2007); https://doi.org/10.1016/j.jhazmat.2006.09.041.

28. S.K. Lagergren, Vetenskapsakad. Handl., 24, 1 (1898).

29. Y.S. Ho and G. McKay, Process Saf. Environ. Prot., 76, 183 (1998); https://doi.org/10.1205/095758298529326.

30. W.J. Weber Jr. and J.C. Morriss, J. Sanit. Eng. Div., 89, 31 (1963).

31. A.B. Albadarin, C. Mangwandi, A.H. Al-Muhtaseb, G.M. Walker, S.J. Allen and M.N.M. Ahmad, Chem. Eng. J., 179, 193 (2012); https://doi.org/10.1016/j.cej.2011.10.080. 